\title{
CONFERÊNCIA
}

\section{QUE MATEMÁTICA PARA FORMAR O FUTURO PROFESSOR? História do saber profissional do professor que ensina matemática}

\author{
Wagner Rodrigues Valentel
}

\section{CONSIDERAÇÕES INICIAIS}

Este texto é resultado sistematizado da conferência de abertura que foi proferida na II Escola de Estudos Avançados Sobre Pesquisa em Cultura, História e Educação Matemática. O evento ocorreu em Belém do Pará, na UFPA, entre os dias 4 a 8 de fevereiro de 2019. Foi promovido pelo Programa de Pós-Graduação em Educação em Ciências e Matemática, em parceria com o GHEMAT Brasil - Associação de Pesquisadores em História da Educação Matemática.

A pergunta do título deste artigo, possivelmente, tempos atrás, careceria de sentido. Que matemática para a formação do professor de matemática? A matemática, obviamente! Mas, tal radicalidade precisa ser atenuada, pelo menos do ponto de vista da letra, da documentação estabelecida nos primórdios dos cursos de licenciatura em matemática. Desde a criação das faculdades de filosofia, da pioneira Faculdade de Filosofia, Ciências e Letras da Universidade de São Paulo, em 1934, a formação do professor de matemática incluía a matemática e as disciplinas pedagógicas. O modelo conhecido por "3+1" reservava a primeira parcela

\footnotetext{
1 Professor Livre Docente do Departamento de Educação da Escola de Filosofia, Letras e Ciências Humanas da Universidade Federal de São Paulo. Possui graduação em Engenharia pela Escola Politécnica da USP e Pedagogia pela Universidade Santa Cecília dos Bandeirantes. Mestrado em História e Filosofia da Educação pela PUC-SP e doutorado em Educação pela FEUSP. Professor dos Programas de Pós-Graduação em Educação e Educação e Saúde da UNIFESP e da REAMEC - Rede Amazônica de Educação em Ciências e Matemática. Pesquisador 1C do CNPq. Coordenador do GHEMAT - Grupo de Pesquisa de História da Educação Matemática - www.ghemat.com.br. E-mail: ghemat.contato@gmail.com
} 
para a matemática, o "3"; a segunda, para as rubricas pedagógicas, o "1". Tal modelo sedimentou a formação de professores de matemática, alijando dessa formação, em grande medida, a capacitação profissional para a docência. A dar crédito às primeiras gerações de professores formados, privilegiava-se o " 3 "2.

Esse modelo de formação de professores de matemática, estudado já por vários pesquisadores, aparta as Ciências da Educação do campo disciplinar matemático. De um lado, o campo disciplinar - a matemática; de outro, a pedagogia. E essa é uma realidade histórica não exclusiva do Brasil3.

Talvez seja possível dizer que um marco importante de aproximação entre o campo pedagógico e o disciplinar matemático tenha sido o da criação da CIEM/IMUK. Em 1908, na cidade de Roma, matemáticos manifestavam preocupação com o ensino da matemática. É a primeira vez que matemáticos reunidos em congresso internacional consideraram ser importante debater questões ligadas ao ensino. Ao que parece, de modo inédito até então, buscava-se internacionalizar o ensino da matemática. David Eugene Smith, professor de matemática do Teachers College de Nova lorque, viu suas intenções, apresentadas em 1905, finalmente serem acatadas. Naquele ano, Smith sugeriu a criação de uma comissão internacional para estudo do ensino de matemática. A comissão foi criada, em Roma, por ocasião do IV Congresso Internacional de Matemáticos. Fica conhecida por CIEM/IMUK. Constituída a comissão, para dirigi-la, foi eleito um comitê central, com a direção dos matemáticos Félix Klein, Henri Fehr e George Greenhill. Os trabalhos se colocaram em andamento. Em questão, uma reforma do ensino da matemática ${ }^{4}$.

\footnotetext{
2 Se do ponto de vista da letra, dos decretos, haveria rubricas pedagógicas, é emblemático o depoimento do matemático e professor Benedito Castrucci, reproduzido em muitos estudos, como os de SILVA (2000) sobre a desvalorização da discussão e formação para o ensino...

3 Os estudos organizados por Hofstetter; Valente (2017) mostram como essa separação historicamente ocorre em países europeus.

${ }_{4} \mathrm{Um}$ estudo aprofundado sobre o tema pode ser lido nos textos organizados por Valente (2004).
} 
Ainda caberia citar que o estabelecimento do campo disciplinar e profissional da Educação Matemática ${ }^{5}$ promoveu uma aproximação maior ainda entre as Ciências da Educação e a Matemática, esta última vista como campo disciplinar.

O fato é que esses acontecimentos pontuam a existência de um movimento progressivo de reflexões e ações sobre a formação de professores de matemática, colocando, de modos diversos, a necessidade de estabelecer referências para o saber profissional do professor de matemática. É esse contexto que dá sentido à questão do título do artigo: Que matemática para formar o futuro professor?

\section{A matemática da cultura escolar e a formação de professores}

Desde a Etnomatemática - vertente criada nos anos 1970, no Brasil, com repercussão internacional - é possível estabelecer que cada cultura tem a sua matemática. Há, então, várias matemáticas. Na especificidade proposta por este texto, vamos nos ater à matemática da cultura escolar. Nesses termos, tomamos como base os estudos de Dominique Julia, que caracteriza a cultura escolar como um conjunto de normativas definidoras de saberes a ensinar e condutas a inculcar; e um conjunto de práticas que possibilitam a transmissão desses saberes e incorporação de modos e condutas. Essas normas e práticas serão sempre orientadas pelas finalidades da escola a cada tempo histórico (JULIA, 2001, p. 10).

E no âmbito da cultura escolar, regida por normas e práticas, são elaboradas as disciplinas escolares. André Chervel mostra como, ao longo do tempo, a escola reelabora os saberes disciplinares construindo novos saberes em forma de disciplinas escolares (CHERVEL, 1990). As disciplinas escolares mostram-se, assim, como um produto histórico do encontro das Ciências da Educação - da Pedagogia, com os campos disciplinares (HOFSTETTER et al., 2009).

\footnotetext{
5 É possível citar como marcos referenciais de criação do novo campo, no Brasil, a realização do I ENEM - Encontro Nacional de Educação Matemática, em 1987, em São Paulo; e, o ano de 1988, quando houve a criação da SBEM - Sociedade Brasileira de Educação Matemática.
} 
Nessa perspectiva teórico-metodológica de estudos históricos investiga-se a matemática da cultura escolar. Como, ao longo do tempo vai sendo elaborada uma matemática a estar presente no ensino? Tal questão envolve, ainda, a formação de professores (HOFSTETTER; VALENTE, 2017): Como vão sendo alterados os saberes matemáticos da formação de professores para ensinar essa matemática do ensino?

Essas interrogações levam-nos a considerar duas matemáticas da cultura escolar. Uma primeira, a matemática presente no ensino, uma matemática a ensinar. Refere-se à matemática como objeto de ensino do professor. $O$ que ele tem que ensinar. Uma segunda matemática leva em conta a formação de professores. Tendo em vista que o professor terá que ensinar uma dada matemática na escola - na Escola Básica, para usar os termos atuais - que matemática deverá participar dessa formação que the permita, Ihe dê condições de melhor exercer o seu ofício docente? E assim, retornamos à questão inicial, agora de modo um tanto mais preciso: Que matemática para ensinar necessita o futuro professor em sua formação? (BERTINI, MORAIS, VALENTE, 2017).

Do modo como foram caracterizadas teoricamente, matemática a ensinar e matemática para ensinar, em cada tempo histórico, estão articuladas. A escola, em cada época, com finalidades que atendem a cada tempo, parametriza-se por normas e práticas que reorganizam os saberes presentes no ensino e na formação de professores.

As pesquisas sobre o saber profissional do professor de matemática em perspectiva histórica intentam evidenciar e tornar inteligíveis as mudanças relativamente à matemática a ensinar e à matemática para ensinar. Ambas, como se mencionou, mostram-se articuladas ao longo tempo. Cabe ao historiador da educação matemática, na verdade, uma tripla tarefa: caracterizar essas matemáticas e mostrar como elas estão relacionadas. 


\section{As pesquisas sobre o saber profissional do professor que ensina matemática}

A admissão, por hipótese teórica de investigação, da existência da matemática a ensinar e da matemática para ensinar tem sustentado pesquisas recentes. A tese de doutorado de Oliveira (2017) mostra-se como um dos primeiros exemplos. O autor caracterizou como foi elaborada em tempos da chamada vaga pedagógica do ensino intuitivo, finais do século XIX e primeiras décadas do XX, a matemática a ensinar, em particular, a aritmética a ensinar nos primeiros anos escolares.

Que transformações sofreu a aritmética do ensino primário ao estar sujeita à vaga intuitiva? Tal interrogação norteia a pesquisa de Oliveira (2017). A escolha do material empírico realizada pelo autor, para a análise da aritmética disposta para o ensino primário no período 1870 a 1920, recai sobre os livros didáticos destinados ao ensino primário. É essa a empiria privilegiada para a análise da aritmética elaborada pela modernidade educacional.

Na extensa análise realizada dos livros didáticos, Oliveira (2017) pôde retirar dela a caracterização de uma aritmética intuitiva. Fruto da modernidade educacional, recriada a partir do método intuitivo,

a Aritmética intuitiva da pedagogia moderna rompeu com a ideia de que Aritmética era um saber exclusivamente escolar. Antes, as questões da vida prática quase nunca eram tratadas, e quando abordadas constituíam tarefas à parte. Com a pedagogia moderna, este novo saber inverteu a lógica, já que não se cogitava ensiná-lo explorando situações reais. Indicou-se que os conteúdos fossem estruturados relacionando a vida social da criança com a vida escolar. Esta foi uma maneira de a criança passar a aprender e apreender a Aritmética na aplicação natural das suas necessidades reais. Desta forma, Aritmética passou a ser uma matéria que dava oportunidade de a criança aplicar na vida social aquilo que aprendia na vida escolar. Uma matéria que extraía da vida social as situações para compor e conduzir as tarefas da vida escolar (OLIVEIRA, 2017, p. 245-246).

Em termos de sua estruturação, o autor mostrou que a aritmética intuitiva se organizava por meio de alguns princípios: 
a) cultivar a inteligência seguindo uma marcha de ensino que coloca o aluno em situações que o auxiliem na descoberta das regras; b) avançar sempre do conhecido para o desconhecido, do próximo ao distante, do simples ao complexo, do fácil ao difícil; c) recusar meios mecânicos que o levem a confiar mais na memorização em vez da inteligência; d) dinamizar o ensino de cada conteúdo para não retomar o hábito da rotina (OLIVEIRA, 2017, p. 247)

Diante dos resultados da pesquisa de Oliveira (2017) tornar-se possível conjecturar sobre processos e dinâmicas que participam da elaboração de saberes cuja finalidade envolve a escolarização, o ensino, a formação. Em resumo, saberes com finalidades educacionais, matemática da cultura escolar.

Pinheiro (2017) também investigou a matemática a ensinar, num outro tempo histórico: tempos da pedagogia científica, vertente do chamado Movimento da Escola Nova.

A autora revelou que com o desenvolvimento da pedagogia científica, as transformações operadas pelo método intuitivo no ensino de aritmética foram submetidas ao crivo da ciência. As primeiras experiências evidenciaram que a ideia de número não era fruto da percepção sensorial, pois as crianças não percebiam os números da mesma maneira que os objetos sensíveis. Os números não poderiam ser vistos tal como os objetos, como por exemplo quando se vê duas cadeiras, três quadros, tendo em vista que aquilo que nós vemos são as cadeiras, os quadros e não o número dois ou três (PINHEIRO, 2017). O que na realidade se faz é "contar as coisas e, como fazemos quase sempre com o auxílio dos olhos, temos a crença de que vemos os números" (AGUAYO, 1936, p. 336 apud PINHEIRO, 2017).

Pinheiro (2017) mostrou, ainda, que estudos sobre a memória, ao tempo da pedagogia científica, revelaram que os objetos são registrados em nossas mentes por meio de impressões, as quais deixam rastros em forma de imagens e eram elas que permitiam lembrar do objeto quando ele não estava presente. Sob essa ótica a percepção dos números seria possível apenas aos quatro primeiros, pois a medida que eles aumentavam em magnitude a percepção diminuía consideravelmente, o que significava que 
eles não poderiam ser percebidos sem que fossem contados. A ideia de que os números chegavam a inteligência por intermédio dos sentidos, pelo uso de objetos, foi colocada em xeque por experiências que defendiam que a aprendizagem dos números ocorreria pelo agrupamento, tal como a lógica de organização do nosso sistema de numeração decimal. Os números não poderiam ser mais vistos como "indivíduos" em separado, ou como um todo em si só. Ao contrário, deveriam ser ensinados como membro de uma escala ou série (PINHEIRO; VALENTE, 2017).

A elaboração, num dado tempo histórico, de uma matéria escolar para o curso primário não se aparta da formação de professores. Há relações entre as instâncias do ensino e da formação que podem ser estudadas pela via dos saberes, das articulações estabelecidas entre os saberes presentes no ensino e daqueles destinados à formação de professores, como se mencionou anteriormente. Essas relações, por certo, são também históricas, isto é, ocorrem de modos diversos a depender da época que se considere.

Uma matéria escolar é objeto de trabalho de professores que conduzem o seu ensino. De outra parte, para que o ensino desta matéria ocorra, há saberes que os professores deverão possuir de modo a poder exercerem o seu ofício, ensinar tal matéria.

Relativamente aos saberes para ensinar, em específico, tratando-se da matemática para ensinar, também há trabalhos já publicados que têm investigado essa ferramenta da docência. Enquanto que a matemática a estar presente no ensino indica o objeto com o qual trabalha o professor, a matemática para ensinar indica o instrumento para esse ensino, uma ferramenta, portanto. Um exemplo de estudo que busca capturar a matemática para ensinar num dado tempo histórico refere-se ao trabalho elaborado por Maciel e Valente (2018). Nele analisa-se o papel dos manuais de pedagogia, que tendo por finalidade orientar o professor no ofício docente, fazem circular uma matemática para ensinar.

O estudo dos autores tomou, em específico, um manual pedagógico que circulou e foi utilizado em escolas normais. Para tal, o texto buscou 
responder à questão: Que elementos de uma matemática para ensinar estão explicitados, objetivados no tratamento dado às rubricas de matemática, abordadas por Silva Pontes, em seu Compêndio de Pedagogia, publicado em 1873?

Maciel e Valente (2018) concluíram que no que diz respeito ao trato com a Aritmética, os aspirantes ao magistério deveriam ter em conta que o início do trabalho pedagógico deveria atentar para a necessidade de posse de um saber importante: o ensino do cálculo oral, o cálculo de modo verbalizado. Tal processo estava distante da tradição colocada pela escola que fazia uso da memória. Este era um saber profissional novo, ensinar oralmente a calcular, sem que houvesse memorização. Afinal, a criança não sabia nem ler, nem escrever ao ingressar no curso primário. Primeiramente os objetos deveriam ser apresentados às crianças, considerados como dispositivos a serviço da intuição. Sendo assim, era necessário que o professor soubesse ensinar pelo método intuitivo.

Um outro novo saber profissional referiu-se ao tratamento a ser dado inicialmente às operações aritméticas. O professor precisava ter ciência de como ultrapassar a tradicional memorização da tabuada. Para tal, profissionalmente, teria que saber como ensinar o cálculo mental. Para ensinar o cálculo mental, o professor já deveria ter realizado com os alunos os cálculos intuitivos por meio de objetos empíricos. Ou seja, primeiramente deveria ensinar as operações com o uso de objetos que faziam parte do universo da criança, depois repeti-las, e com esforço e hábito, os resultados desse trabalho seriam confiados à memória. As operações seriam mais facilmente memorizadas se o ensino se desse por processos intuitivos. A memória viria pelo entendimento das operações com objetos concretos e não, pelo fato do aluno ter sido levado a decorar a tabuada. Como se vê, um saber que o professor deveria possuir muito distinto do que já estava assentado há muito tempo nas práticas dos professores da escola dita "tradicional".

O "método da aritmética" de Silva Pontes, no dizer dos autores, reunia uma aritmética para ensinar que buscava uma ruptura com a tradição. Não 
bastava ao aspirante a professor realizar o que a sua vida de aluno do curso primário provavelmente havia consagrado: o uso da palmatória como instrumento profissional do mestre, acionando-a todas as vezes que o aluno errasse os valores que deveria decorar vindos das tabuadas. A nova aritmética para ensinar, bem entendido, não prescindia de todos os conteúdos de ensino já tradicionalmente organizados. Estava ela articulada a uma aritmética a ensinar, posta nos manuais de aritmética dos tempos de Silva Pontes. Como bem notou o autor, não haveria que se discutir muito a marcha do ensino, pois ela está transcrita nos livros didáticos adotados pelos programas de ensino.

Por fim, os autores concluíram que o Compêndio de Silva Pontes se revelou como documento importantíssimo que sistematizou e objetivou um saber profissional de seu tempo. Uma obra guia "para moços aspirantes ao magistério". Para tornar-se professor a um tempo em que era bastante ter já cursado o ensino primário. Imerso num contexto internacional da vaga intuitiva, o Compêndio organizou uma matemática para ensinar. Sem deixar de mostrá-la articulada a uma matemática a ensinar. E tal conclusão mostrou-se ainda mais verdadeira para a Aritmética, na indicação de uma aritmética para ensinar.

\section{CONSIDERAÇÕES FINAIS}

Nestas considerações finais, retomemos a pergunta inicial: Que matemática para formar o futuro professor? Há uma gama enorme de estudos que vêm sendo realizados buscando caracterizar essa matemática. No entanto, ao que parece, não há estudos de em número suficiente de modo a que as lições vindas da história possam tornar inteligíveis processos e dinâmicas que, ao longo do tempo, vêm elaborando matemáticas a ensinar e matemáticas para ensinar.

Os estudos históricos revestem-se de importância pois possibilitam compreender, por exemplo, que mudanças culturais, mudanças na cultura escolar envolvem muitas décadas. Além disso, ajudam no entendimento das 
razões de existência de rubricas de formação presentes nos currículos dos cursos de licenciatura, do modo com elas se apresentam hoje.

Sem levar em consideração a complexidade dos processos de elaboração de matemáticas a ensinar e matemáticas para ensinar, além das dinâmicas de relacionamento dessas matemáticas, qualquer proposta futura de transformação curricular tende a pouco modificar panoramas considerados insatisfatórios para a formação de professores que ensinam matemática.

Um outro ponto que pode ser considerado fundamental liga-se à busca do saber profissional do professor de matemática. Se há, já de longa data, um movimento que mostra que esse profissional não se caracteriza tão somente pela posse do saber disciplinar - a matemática - pergunta-se: que saber da docência em matemática o identifica? A ruptura com o modelo "3+1" implica na ultrapassagem da separação da pedagogia e da matemática. A primeira tão somente sendo considerada com "lubrificante", no dizer de Chervel (1990), para ensino da segunda. Há que serem caracterizados os saberes de formação do professor, com status de saber. Será necessário investigar como vem sendo elaborada a matemática para ensinar. É preciso levar adiante a investigação teórica que mostre como "informações dispersas são promovidas à condição de saber", parafraseando a escrita do último livro de Peter Burke (2015).

\section{REFERÊNCIAS}

BERTINI, L. F.; MORAIS, R. S.; VALENTE, W. R. A matemática a ensinar e a matemática para ensinar - novos estudos sobre a formação de professores. São Paulo: L F Editorial, 2017.

BURKE, P. O que é história do conhecimento? São Paulo: UNESP, 2015.

CHERVEL, A. História das disciplinas escolares: reflexões sobre um campo de pesquisa. Teoria \& Educação, n. 2, p. 177-229, 1990.

JULIA, D. A cultura escolar como objeto histórico. Revista Brasileira de História da Educação. No. 1. Jan./Jun. 2001, p. 10-43. 
HOFSTETTER, R. et al. Savoirs en (trans)formation - Au cœur des professions de l'enseignement et de la formation. Bruxelles: Éditions De Boeck Université, 2009.

HOFSTETTER, R.; VALENTE, W. R. (orgs.) Saberes em (trans)formação: tema central da formação de professores. São Paulo: L F Editorial, 2017.

MACIEL, V. B.; VALENTE, W. R. Elementos do saber profissional do professor que ensina matemática: o Compêndio de Pedagogia de Antônio Marciano da Silva Pontes. Amazônia (UFPA), v. 14, p. 165, 2018.

OLIVEIRA, M. A. D. A aritmética escolar e o método intuitivo: um novo saber para o curso primário (1870 - 1920). 280f. Tese (Doutorado em Ciências) Universidade Federal de São Paulo. São Paulo, 2017. Disponível em < https://repositorio.ufsc.br/handle/123456789/178956>. Acesso em 05 de maio de 2018.

PINHEIRO, N. V. L. A Aritmética sob medida: a matemática em tempos da pedagogia científica. 224f. Tese (Doutorado em Ciências). Universidade Federal de São Paulo: Guarulhos, 2017. Disponível em <https://repositorio.ufsc.br/handle/123456789/179942>. Acesso em 05 de maio de 2018.

PINHEIRO, N. V. L.; VALENTE, W. R. Binet e o ensino e a aprendizagem da aritmética nos primeiros anos escolares: o que ensinar, quando ensinar.

Revista Atos de Pesquisa em Educação, Blumenau, v. 2, n. 2, mai./ago. 2017. 346 - 362. Disponível em

<http://proxy.furb.br/ojs/index.php/atosdepesquisa/article/view/6338>. Acesso em 10 de maio de 2018.

SILVA, C. M. S. A Faculdade de Filosofia, Cências e Letras da USP e a formação de professores de matemática, 2000.

http://23reuniao.anped.org.br/textos/1925p_poster.PDF

VALENTE, W. R. (org.) Euclides Roxo e a modernização do ensino da matemática no Brasil. 2. ed. Brasília: Editora da Universidade de Brasília, 2004. v. 1. 180p. 